\title{
The Influence of Chinese Stress on English Pronunciation Teaching and Learning
}

\author{
Fuying $\operatorname{Bian}^{1}$ \\ ${ }^{1}$ School of Foreign Languages, Jinan University, Jinan, Shandong Province, China \\ Correspondence: Bian Fuying, School of Foreign Languages, Jinan University, No. 336, West Nanxinzhuang \\ Road, Jinan, 250022, Shandong Province, China. E-mail: 2263143873@qq.com
}

Received: August 8, 2013 Accepted: September 26, 2013 Online Published: October 10, 2013

doi:10.5539/elt.v6n11p199 URL: http://dx.doi.org/10.5539/elt.v6n11p199

\begin{abstract}
Stress is one of the key suprasegmentals in English sound system. It plays an important role in intelligibility and comprehensibility. However, stress often poses problems for Chinese EFL Learners. Chinese learners of English often misplace the stress in English words and sentences which subsequently may interrupt the flow of communication and lead to unintelligibility. Therefore, the correct placement of stress is a main concern in EFL speech intelligibility and training, and it is particularly important for Chinese learners of English because they have a drastically different stress system in their native language. There is evidence to suggest that the transfer of native language sound systems is one of the major reasons for foreign language pronunciation errors. This paper examines the differences between Chinese and English stress. Based on such contrastive analysis of English and Chinese stress, experiments are conducted to investigate the reasons for Chinese EFL learners' pronunciation difficulties in English stress, and finally implications for English pronunciation teaching are drawn.
\end{abstract}

Keywords: Chinese EFL learners, phonological transfer, stress misplacement, English stress teaching

\section{Introduction}

Unlike the children in their native language acquisition, the ESL/EFL learners come to the task of English acquisition with the knowledge of at least one other language. Prior knowledge and experience of one or more languages often condition the way the ESL/EFL learners make sense of any new experience of language learning. The use of the native language (or other language) information in the acquisition of an L2 (or additional language) is called language transfer (Gass, 1979). Evidence for transfer in all aspects of language is now abundant - phonology, syntax, semantics, and pragmatics. Although it is difficult to quantify the extent of transfer at different language levels, it is widely accepted that the transfer at the level of phonology is more remarkable than that of other linguistic levels (Ellis, 1994). The existence of 'foreign accents' in L2 learning is so well attested that it hardly requires documenting. In general, native speakers have little difficulty in distinguishing the language background of different learners (Ellis, 1994). As Purcell and Suter (1980) have shown, the L1 of learners serves as the best predictor of native speakers' evaluation of their speech. Therefore, it is quite reasonable to say that the nature of a foreign accent is determined to a large extent by a learner's native language (Avery \& Ehrlich, 1992), and the pronunciation errors made by second language learners are the reflections of the sound inventory, rules of combining sounds, and the stress and intonation patterns of their native language (Swan \& Smith, 1987).

English and Chinese belong to two different language families, and have many significant differences in their phonological systems. For example, English has more vowel sounds than Chinese; Chinese has no distinction between long and short vowels; some English phonemes do not exist in Chinese; and their stress and intonation patterns are different (Chao, 1968; Cheng, 1973; Yang, 1987; Wei, 2003; Ou, 2006). The difficulties of pronouncing individual English words, compounded by problems with rhythm and intonation, result in the heavily accented English of many Chinese learners. Research shows that in learning English Chinese learners are often interfered with by their native language, especially at the level of phonology (Gui, 1978; Fan, 1982; Chen, 1987; He, 2002; Wei, 2003; Zhao, 2006; Gao \& Deng, 2009). Therefore, it is necessary for Chinese teachers of English to realize the impact of Chinese on English pronunciation learning and teaching. In order to identify English pronunciation difficulties caused by Chinese phonological transfer, Chinese teachers of English need to be more aware of the similarities and differences between English and Chinese sound systems. 
The sound system of English includes two parts: segmentals and suprasegmentals. Segmentals include individual vowels and consonants, and suprasegmentals comprise stress, pitch contour or intonation, and rhythm (Seferoglu, 2005). It is difficult to say which of them is more important. However, there is evidence to indicate that faulty suprasegmental features may affect intelligibility and comprehensibility more adversely than segmental errors (Carroll, 2000). As stress contributes to English rhythm and intonation (Scarcella \& Oxford, 1992), this paper will, based on the theory of language transfer, focus on the Chinese stress pattern as a source of interference in English pronunciation learning.

\section{Literature Review}

\subsection{Definitions of Language Transfer}

The notion of transfer is one of the key concepts in the behaviorist school. Language transfer refers to speakers or writers applying knowledge from their native language to a second language (Wikipedia, 2013). In practice, transfer has attracted people of different academic backgrounds and led researchers to different interpretations and definitions of the term. Sharwood-Smith and Kellerman (1986) have argued that a superordinate term that is theory-neutral is needed and suggest crosslinguistic influence. In their opinion, the term 'crosslinguistic influence' is theory-neutral, allowing one to subsume under one heading such phenomena as 'transfer', 'interference', 'avoidance', 'borrowing' and L2-related aspects of language loss and thus permitting discussion of the similarities and differences between these phenomena. Odlin (1989) offers his working definition of transfer as a basis for his own thoughtful treatment of such phenomena, and his definition provides an adequate basis for the material to be considered in this paper. In his opinion, "Transfer is the influence resulting from the similarities and differences between the target language and any other language that has been previously (and perhaps imperfectly) acquired". Where the two languages are identical or similar, learning can take place easily through positive transfer of the native language pattern, but where they are different, learning difficulty arises and errors resulting from negative transfer are likely to occur (Ellis, 1994). For instance, English consonants /b/, $/ \mathrm{p} /, / \mathrm{d} /, / \mathrm{t} /, / \mathrm{g} /, / \mathrm{k} /$ are similar to Chinese $b, p, d, t, g, k$, Chinese learners of English can acquire them with ease. However, some English phonemes, such as $/ \mathrm{i} /, / \mathrm{N} /, / \theta /, / \mathrm{J} /, / \mathrm{d} /$ do not exist in Chinese, so it is more difficult for Chinese learners of English to acquire them. Sometimes, influenced by their native language, the Chinese learners will probably replace them with their similar counterparts of $i, a, s, o, z$ in Chinese. Hence, negative transfer or interference occurs and results in errors.

The question of what is more likely to be transferred from L1 to L2 and how the mechanism of transfer works has given rise to different linguistic models and hypotheses over the last two decades. One of the earlier hypotheses on cross-linguistic influence, the Contrastive Analysis Hypothesis tried to predict the likelihood of linguistic transfer in second language acquisition based on the similarities as well as differences between various aspects of L1 and L2. That is, similarities in linguistic structures in two languages will result in positive transfer, while differences will create an interference which is known as negative transfer. Another theory underlying language transfer is a theory of markedness. The core hypothesis of markedness theory concerns correlations, i.e. pairs of "marked" (least distributed) and "unmarked" (more distributed) structural entities in the language. According to this theory, those linguistic phenomena in the target language which are more marked than the corresponding phenomena in the native language will be more difficult to learn.

In addition to the language transfer theory that has been briefly discussed above, different psycholinguistic factors, like metalinguistic awareness, processing demands, language proficiency, etc., have been reflected in studies on cross-linguistic influence.

\subsection{Transfer in Chinese Learners' English Pronunciation Learning}

The influence of native language on foreign language learning has aroused widespread attention of the researchers. Comprehensive studies on transfers were found in Richards (1974), Richards \& Gloria (1974), Corder (1992), Ellis (1994), Odlin (1989), Hammerly (1991), Larsen-Freeman \& Long (1991), Carroll (2000), Goodluck (2000) and Altmann (2006). They all helped to display that transfers are at all the linguistic levels, phonological, lexical, syntactical and semantic. It is, in fact, very difficult to quantify the extent of transfer in the different language levels. There is, however, a theoretical reason for expecting the influence of the L1 to be felt more strongly in pronunciation than in syntax. It is probably because most learners have a much more highly developed metalingual awareness of grammatical properties than of phonological properties (Ellis, 1994). This awareness may enable learners to control their choice of linguistic form at the level grammar to a greater extent than at the level of phonology and this may inhibit transfer.

English is taught as a foreign language in China. Emphasis on how to teach and learn English led to practice of linguistic and non-linguistic contrasting that has resulted in nearly 1000 articles since 1949 (Li, 1996). It was 
reported that transfer by Chinese learners of English occurred at all linguistic levels, phonology, lexis, discourse and syntax.

At the level of phonology, Gui (1978) examined the differences between Chinese and English in terms of phoneme, tone, intonation, rhythm, and juncture. Fan (1982) compared the sound systems of the two languages. Jin (1986) considered the interlingual phonetic features of the Chinese learners. Chen (1987) focused on the sound pitch differences of the two languages. Wang (1990) conducted an experiment to detect that fluctuations played a cardinal role in distinguishing English and Chinese apart: English is prominence-related while Chinese tone-determined. Gong (1991) looked at the interlingual status of the learners in terms of Chinese influence in English intonation. He (2002) and Wei (2003) made contrastive studies on Chinese and English word stress patterns. Gao and Deng (2009) conducted a corpus-based study on Chinese college students' word stress misplacement and found that improper assignment of word stress is common among Chinese non-English majors.

All these imply possible Chinese-based phonological transfers in all these aspects into the learning English as a foreign language. However, experimental studies which focus on the influence of Chinese stress on English stress learning are quite rare. Next, this paper will examine the differences between Chinese and English stress. Based on such contrastive analysis of English and Chinese stress, experiments are conducted to investigate the reasons for Chinese EFL learners' pronunciation difficulties in English stress.

\section{Contrastive Analysis of English and Chinese Stress}

Although contrastive analysis has often been criticized for its inadequacy to predict the transfer errors that learners will make in actual learning contexts (Whitman \& Jackson, 1972), it cannot be denied that "such interference does exist and can explain difficulties" (Brown, 1994), especially in the phonological aspects of L2 learning. In this sense, the significance of contrastive analysis may not necessarily lie in the predictability of transfer errors, but rather in the explanatory potential of learner errors that teachers encounter in their daily practices (Celce-Murcia \& Hawkins, 1985).

\subsection{Stress}

In any language, speakers do not produce vowels with the same prominence. Those that are perceived as relatively more prominent than others are said to be stressed. Stress refers to "the greater prominence or loudness that a vowel or syllable exhibits within a word, in at least two degrees: strong/weak (or primary/secondary)" (Teschner \& Whitley, 2004). According to Fry (1958), stress is the result of the interaction of pitch, intensity, and duration. A stressed syllable is often louder and longer than an unstressed syllable. Stress gives a certain basic prominence to the syllables, and hence to the words, on which it is used, and incidentally assists in avoiding monotony.

Stress usually falls into two types according to the way it is presented. When it is considered in the linguistic environment of a word (including compound) being in isolation, it is called word stress. When it comes to a sentence (including phrase) that represents a form of connected speech, it is termed sentence stress.

\subsection{English Word Stress}

Word stress means one or more of the syllables in a word are more prominent than other syllables (Clark \& Yallop, 2000). The most highly stressed syllable receives the primary stress, while the other stressed ones are marked as having secondary stress. In actual production, however, it is the primary stress of words that is most important for meaning (Cruttenden, 2001).

Despite the fact that there is no simple rule that governs the happening of word stress, some general principles have been recognized, which the learners may observe to facilitate themselves in pronouncing English content words (Li, 1999). As we have known, all monosyllabic words are stressed. Multisyllabic words often vary in their stress patterns. Consider the groups of words below.

1) Two-syllable words: 'paper 'napkin 'chairman 'penny

2) Words of three or more syllables: te'legraphy pho'tography e'conomy 'family 'capital

3) Words with suffixes: 'clarity 'greenish dic'tation tele'graphic com'panion ci'vilian

4) Same spelling, different words:

a) 'produce (n.) pro'duce (v.)

b) 'present (n./adj.) pre'sent (v.)

c) 'abstract (n./adj.) ab'stract (v.) 
d) 'increase (n.) in'crease (v.)

An observation of these lists of words will provide a general picture of the stress patterns of English multisyllabic words. Most words of two syllables have their stress on the first syllable, words of three or more syllables are stressed on the third syllable from the end, and words suffixed with -ity, -ish, -ion, -ic, -ian, etc. nearly always show their stress on the syllable immediately before the suffix (Li, 1999). A shift of stress occurs in Group D; words that are spelled identically but function as different parts of speech have different stress patterns. If it is a verb, the stress falls on the second syllable; if it is a noun or an adjective, the stress falls on the first syllable. Some pairs possess the same or approximately the same meaning, but some pairs are semantically quite different. More often than not, this happens in noun/verb or adjective/verb pairs.

Alterations of stress that are similar to those happening in Group D occur between compounds and free phrases in Group E. Consider:

5) e) 'greenhouse (a house with sides and roof of glass, kept warm for growing plants)

'green'house (a house of a green color)

f) 'blackbird (a common European singing bird)

'black 'bird (a bird of black color)

g) 'darkroom (a dark room in which photos can be processed)

'dark 'room (a room which is dark)

These contrasting pairs are minimal in that although both members of each pair are made of identical words, the first member is a compound while the second member is a free phrase. They are distinguished not only by their stress patterns but also by how they are interpreted for meaning. Compounds and phrases in English use different stress patterns because they are structurally different: the former are morphological linguistic units, but the latter are syntactically organized. Still the stress distribution may vary, because it provides a firm basis not so much between the ways in which compounds and phrases are structured as between different semantic relations.

From the above analysis, we can see that at the lexical level, every English word has a definite place for the stress and we are not allowed to change it. If we stress the wrong syllable, it spoils the shape of the word for an English hearer and he may have difficulty in recognizing the word. Therefore, stress is an essential feature of word identity in English (Kenworthy, 1987). It can discriminate the semantic meanings and parts of speech (Roach, 2003; Cruttenden, 2002; Trevian, 2007).

The possible arrangements of strong and weak syllables within words are not equally represented within the lexical repertoire of English. The most common word type in English is two-syllable words with a strong initial syllable and a weak second syllable (Garlson, Elenius, Granstrom, \& Hunnicutt, 1985). Only about a quarter of the words of English are weak-initial polysyllables (Gutler \& Garter, 1987). Moreover, many weak-initial words have a low frequency of occurrence in natural speech; in a corpus of 200,000 words of spontaneous British English conversation, Gutler and Garter (1987) find that weak-initial polysyllabic content words account for only about $4 \%$ of all words and an English listener is three times more likely to encounter a word with the primary stress on the first syllable than on other syllables. Thus there is a marked asymmetry, both in the vocabulary and even more so in natural speech, with regard to how often particular stress patterns occur. From the analysis, we can say English is left-prominent for its metrical structure. That is, most English words begin with a strong syllable.

\subsection{English Sentence Stress}

Sentence stress means the relative degree of force given to the different words in a sentence (Clark \& Yallop, 2000). The semantic relationship among the constituent members determines the stress pattern of a sentence. In English, words are divided into two categories: lexical (content) words and function (structure) words. It is the content words that are generally important; function words have little or no meaning but serve to connect the content words to form a grammatical unit such as sentence. Even the content words are not of the same significance to the meaning of a syntactic structure. The relative importance of words, therefore, provides a basis for determining their relative stress.

I did it in the 'classroom. (I did it in the classroom, not in the bedroom.)

I did it 'in the classroom. (I did it in the classroom, not outside of it.)

'I did it in the classroom. (It is me, not anybody else, who did it here.)

These examples help illustrate a number of facts in English stress distribution. First, in an English sentence, it is 
the content words that usually receive stress (Altmann, 2006). Second, even a content word may be unstressed when it is less important than others (McCarthy, 1991). Third, stress falls on a function word only when it calls special attention to the meaning it conveys (Kupier \& Allan, 1996). All these taken into account, it may well be said that a sentence can be stressed in different ways depending on the particular meaning or emphasis it is intended, but not without rules.

Variations in stress distribution do not just alter the semantic relations among words of a sentence; they also affect the physical appearance of an utterance. In English, stresses occur at regular intervals, which form the rhythm of speech. Stress is thus the basis of rhythm, which represents the regularity of strong stresses and weak stresses in speech (Gussenhoven \& Jacobs, 2001). English is a stress-timed language, which implies that the period of time from each stressed syllable to the next is approximately the same, irrespective of the number of intervening unstressed syllables (Roach, 2003). That is to say, the amount of time it takes to say a sentence in stress-timed language is largely determined by the number of stressed syllables, not by the total number of syllables (Avery \& Ehrlich, 1992). For example, the following two English sentences occupy the same length of time though they have different numbers of syllables.

'Cats/'eat/'fish. (3 syllables, 3 stressed syllables, 3 beats)

The 'cats/have 'eaten/the 'fish. ( 7 syllables, 3 stressed syllables, 3 beats)

That is, the speed of utterance in connected English speech depends on the number of stressed syllables. The greater the number of stressed syllables, the more slowly they are read whereas the greater the number of unstressed syllables, the more rapidly they are produced (Underhill, 1998). This feature of English rhythm has great influence upon the speed of utterance and the length of sounds, especially the vowels. To speak rhythmically, native speakers compress the intervening unstressed syllables as much as possible so that time is shortened and the regularity of the intervals is maintained. When there are many such syllables, native speakers utter the syllables rapidly. Compressing of unstressed syllables is achieved by a number of techniques known as weakening of vowels, elision, assimilation, pause and linking.

The rhythmic pattern of English, together with the elements mentioned above, all quite unique to English pronunciation, is a potential difficulty for English learners, especially those whose native language has syllable-timed rhythm such as Chinese (Cruttenden, 2002). In syllable-timed languages, the syllables follow each other at roughly equal intervals of time. To put it another way, in syllable-timed languages, it is the number of syllables, not the number of stressed syllables that determines the amount of time to say a sentence (Roach, 2003). For instance, in Chinese, each of the equivalent sentences of English examples above would take different amount of time to complete each of the sentences:

'Mao/'chi/'yu. (3 syllables, 3 stressed syllables, 3 beats)

'Mao/'chi 'wan 'le/'yu. (5 syllables, 5 stressed syllables, 3 beats)

As is apparent from these examples, it takes different length of time to produce the two Chinese sentences because they have different numbers of syllables.

\subsection{Chinese Word Stress}

In Chinese, stress is not as significant as that in English due to the existence of tones that make stress in Chinese not so prominent. Similar to the stress of English, pitch, intensity, and duration are the three factors that lead to the realization of stress in Chinese (Chao, 1968). Although stress in both English and Chinese shares similar features, such as higher in pitch and greater in intensity and length, it has different functions in English and Chinese. Stress in English can differentiate the meaning of words while in Chinese it cannot (Wei, 2003). In Chinese, it is the tone that contrasts the meaning of words (Zhao, 2006). Chinese is a tone language (Roach, 2003). In such a language, prominence is mainly achieved by variations in pitch level. Tone languages have contrasting pitches; the same string of segmental sounds will have different meanings when pronounced with different tones. This means that a language is thought to have tones when differences in pitch signal differences in lexical meanings. Chinese is such a language. In Chinese, almost every word has only one syllable (Kelly, 2000), and each syllable has an inherent pitch contour, and thus minimal pairs (or larger minimal sets) exist between syllables with the same segmental features but different tones. Modern standard Chinese pronunciation has five linguistic tones: high level (Tone 1, -), rising (Tone 2, '), falling-rising (Tone 3, '), falling (Tone 4, ' ), and neutral tone. Neutral tone has no specific contour; its pitch depends on the tones of the preceding and following syllables. Chinese speakers refer to this tone as the 'light tone'. This tone occurs only on unstressed syllables. These five tones, when applied to the same sequence of sounds, represent different meanings. When a speaker of Chinese pronounces the form $m a$ as $m \bar{a}$, $m a ́$, $m a ̆$, mà, and $m a$, he may be reading the five Chinese 
characters 妈，麻，马，骂 and 吗 meaning respectively “mum", "hemp”, "horse", "scold", and “an interrogative particle". That is to say, the meaning of a Chinese word is decided by the pitch level of the syllable. The pitch and the change in pitch of a syllable mark for the difference in lexical meaning. Due to this reason, stress in Chinese does not play the same role as that in English. For example, the Chinese disyllabic word 葡萄 (grape) can be read with the first syllable stressed as 'putao or the second syllable stressed as pu'tao without changing the meaning of the word. Therefore, we can see that compared with the tones, stress seems to be of less importance in discriminating lexical meaning in Chinese.

At the lexical level, stress in English can differentiate the meaning of words while in Chinese, it is the tone that contrasts meaning of words. The differences between these two languages may cause problems for Chinese learners in learning English stress. Some Chinese learners might use different tones to indicate different English lexical meanings. Juffs (1990) found that Chinese speakers used Tone 1 with an inordinate degree of length to indicate lexical stress. For Cantonese speakers, Chao (1980) indicated that they associated high and low tones with stressed and unstressed syllables. The Chinese subjects in Archibald's (1997) study did not seem to have acquired principles of English stress assignment. They appeared to treat stress as a purely lexical phenomenon in the same way they treat tone. All these have been attributed to the prosodic transfer of Chinese tones. Then, does Chinese stress exert influence on Chinese learners' learning of English stress? Obviously, the answer is yes. Some researchers have shown that Chinese speakers, with a tonal background, have problems in acquiring English lexical stress. Since many students may transfer their mother tongue stress patterns to English (Archibald, 1997; Guion, 2006), presented next is an analysis of the interference due to Chinese word stress patterns.

\subsection{The Influence of Chinese Word Stress on English Stress Learning}

Before starting the study of this issue, however, it is necessary to have a brief view of the Chinese word stress patterns. According to the traditional views, it is agreed that Chinese word stress patterns fall mainly into four basic types -2 1, 10,231 and 2331 standing for disyllabic, trisyllabic and quadrisyllabic words respectively (the numbers 1, 2, 3, 0 correspond to primary, secondary, tertiary and weak/neutral stresses) (Chao, 1968; Xu, 1980; Zhou, 1980; He, 2002). For instance,

$\begin{array}{lll}\text { Chinese Words } & \text { Stress Patterns } & \text { English Words } \\ \text { (1) huoche } & 21 & \text { train } \\ \text { (2) tushu } & 21 & \text { book } \\ \text { (3) putao } & 10 & \text { grape } \\ \text { (4) xiaojie } & 10 & \text { miss } \\ \text { (5) huchezhan } & 231 & \text { railway station } \\ \text { (6) tushuguan } & 231 & \text { library } \\ \text { (7) disanxiasi } & 2331 & \text { obsequious } \\ \text { (8) huanhuanxixi } & 2331 & \text { happy }\end{array}$

As disyllabic words account for a major part of Chinese (Hu, 1981; Chen, 1984), the discussion will therefore begin with the disyllabic stress patterns. Chinese disyllables have the stress patterns of 21 and 10 (Chao, 1968; Chen, 1984) as shown in the above examples (1), (2), (3) and (4). But a comparison between the similar stress patterns in both Chinese and English will reveal that the English weak-strong pattern (e.g. unless, forget, connect etc.) are not in conformity with its Chinese counterpart, though its strong-weak pattern (e.g., nation, people, pretty etc.) is quite similar to the one in Chinese. In English, un- in unless, for- in forgot, and con- in connect are not realized as [วn], [fว], and [kวn] phonetically, but as [ən], [fə], and [kən]. So it is clear that English has a vowel reduction rule that can be explicitly stated as: A syllable, when preceding a stressed vowel, will have its vowel reduced in quality as schwa [ə]. However, in Chinese, at least in normal speech, no such changes occur, with the exception of only some cases with the pattern strong-weak having vowel reduction in the final, for example, the Chinese disyllabic words 妈妈 (mother) can be read as [mAmA] or with its second vowel reduced to schwa /a/ as [mAmə], but never as [məmA]. Therefore, in disyllabic words, Chinese stress pattern weak-strong is not equal to the stress pattern weak-strong in English. In English a syllable preceding the word stress often gets its vowel reduced to schwa/a/ (or other reduced form) and the change of stress is accompanied by the reduction of the vowel, however, this phenomenon does not occur in Chinese disyllabic words.

From examples (1)-(8), we can see that 1) Chinese has much higher frequency in using secondary stress, not only in disyllabic but also in trisyllabic and quadrisyllabic words; 2) most Chinese words have their primary 
stress on the final syllable with the exception of the disyllabic words ending with a neutral tone, such as examples (3) and (4). According to Lin, Yan and Sun (1984), there are some 30,000 disyllabic words (including compounds) in a large modern Chinese dictionary, and about 2,000 are stressed on the first syllable. That is to say, in more than $80 \%$ of disyllabic words, the final syllable is heavier than the first syllable. Lin, Yan and Sun's (1984) conclusions conform to Chao's (1968) opinion. According to their analyses (Chao, 1968; Lin, Yan \& Sun, 1984), Chinese is right-prominent for its metrical structure.

By contrast, English is left-prominent for its metrical structure. This cross-linguistic difference in stress patterns results in Chinese learners' misplacement of word stress in English words (Gui, 1978; He, 2002). As a result, Chinese EFL learners quite frequently mispronounce English words by placing the primary stress on the final syllable. The transference of Chinese word stress patterns can also be seen in Chinese students' learning of English compounds. For instance, many Chinese EFL learners, when asked to mark stress, often put recorder 'player (for 'recorder player), sports 'ground (for 'sports ground), and language 'teacher (for 'language teacher). This shows that the Chinese students' transference of the stress pattern of Chinese compounds is apparently present in the production of their English counterparts. Influenced by the stress pattern of Chinese compounds, Chinese students are likely to use the weak-strong pattern instead of the strong-weak in English. Hence instead of producing the correct stress forms for the English compounds 'recorder player, 'sports ground, and 'language teacher, the students are liable to shift the main stress to the final syllable, leading to the errors of recorder 'player, sports 'ground, and language 'teacher. This phonological transference of Chinese stress patterns in English pronunciation learning will be further demonstrated by the following experiment results.

\subsubsection{Experiment 1}

According to the above analysis, an experiment was conducted to investigate the interference from the Chinese disyllabic stress pattern weak-strong by means of carefully arranged materials.

\section{Materials}

10 words were deliberately selected for this experiment. Some of them involve a stress on the first syllable, some on the second. The ten words appear as follows.

(1) origin (2) forgot (3) unless (4) context (5) connect

(6) obtain (7) content (8) original(9) congress (10) opinion

\section{Subject}

10 students, 5 males and 5 females, were randomly chosen to participate in this experiment. All of them were first-year college students and had learned English as a foreign language for at least 6 years, and none of them had prior information about the issue under examination.

Method

Each subject was given the ten words as listed in materials required to read for recording. The speaker was allowed to repeat any word until finally s/he thought his or her utterance was satisfactorily produced.

Auditory analysis of the experiment was conducted after the recording was complete. Three professional Chinese teachers of English listened independently to the tape recording and were required to use International Phonetic Alphabet (IPA) to note down the actual production (especially the vowels) of each word uttered by each individual speaker.

\section{Results and Discussion}

The results of this experiment are presented in Table 1, where the number of errors made by each speaker is indicated, and Table 2 is the percentage of errors made for each word.

Table 1 . The percentage of errors made by each subject in the initial vowel quality

\begin{tabular}{|l|l|l|l|l|l|l|l|l|l|l|l|}
\hline \multirow{2}{*}{ Subjects } & \multicolumn{9}{|l|}{ Word Number } & \multicolumn{10}{|l|}{ Percentage of Errors (\%) } \\
\cline { 2 - 12 } & 1 & 2 & 3 & 4 & 5 & 6 & 7 & 8 & 9 & 10 & \\
\hline 1 & & I & I & & I & I & & & & I & 50 \\
\hline 2 & & I & & & I & I & & I & & & 40 \\
\hline 3 & & & I & & I & I & & & I & I & 50 \\
\hline
\end{tabular}




\begin{tabular}{|l|l|l|l|l|l|l|l|l|l|l|l|}
\hline 4 & & I & I & & & I & & I & & I & 50 \\
\hline 5 & & & I & & & I & & I & I & I & 50 \\
\hline 6 & & I & & & & I & I & I & & I & 50 \\
\hline 7 & & & I & & I & I & & & & I & 40 \\
\hline 8 & & & & & & I & & I & & I & 30 \\
\hline 9 & & & I & & & & I & I & & I & 40 \\
\hline 10 & & & & & & I & I & I & & & 30 \\
\hline
\end{tabular}

Notes: "I" indicates the one being incorrect, while all the rest are correct.

Table 2. The percentage of errors made for each word

\begin{tabular}{lllllllllllll}
\hline Word Number & 1 & 2 & 3 & 4 & 5 & 6 & 7 & 8 & 9 & 10 & $\begin{array}{l}\text { Average } \\
\text { Percentage (\%) }\end{array}$ \\
\hline $\begin{array}{l}\text { Percentage for } \\
\text { Each Word (\%) }\end{array}$ & 0 & 40 & 60 & 0 & 40 & 90 & 30 & 70 & 30 & 70 & 44 \\
\hline
\end{tabular}

Stress in English is closely associated with vowel quality. Therefore, as the stress is reduced in a syllable, vowel quality is also reduced. Ladefoged (1982) has illustrated that there is no exception to this process, even at sentence level, where the word has [hæz] has a number of weak forms in addition to the strong form [hæz], for example, [həz], [əz], [z], [s]. When it is in the sentence he has left, it is actually uttered as [hi həz left]. In normal speech, the strong form of has is rarely used. Vowel reduction is really a matter of stress deletion.

Yet, in my experiment, the results clearly show a general tendency for the subjects to use the strong form---to

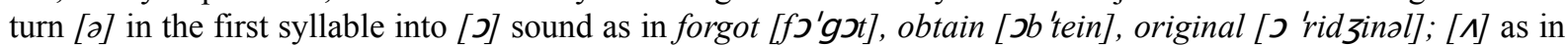

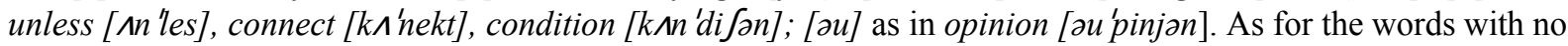
reduced vowels, it turns out they are all very well produced, such as 1, 4, 7 and 9 in Table 1, while in the rest of the seven cases errors amount to very high percentage with the lowest being $40 \%$, as indicated in Table 2 . Here the percentage of errors regarding particular words or subjects will be totally neglected since my interest only lies in what is common and universal to Chinese learners of English.

In the experiment I found that the explanation of the phenomenon, i.e., the transference from $/ \partial /$ to $/ \partial /$, is that more stress is given to the first syllable that should be unstressed and result in a schwa /o/. However, it is argued that this is not only a simple case of changing $/ \partial /$ to $/ J /$ or $/ \mathrm{N}$, but a manifestation of inherent interlinguistic stress pattern transference. The second experiment in the next part will further illustrate this point. Here, the question of why $/ \partial /$ is realized as $/ \partial$ under some conditions and $/ N$ in others, etc. will not be further pursued within the present paper.

\subsubsection{Experiment 2}

This experiment further investigates the interference of Chinese stress patterns on the Chinese students' learning of English compounds.

\section{Materials}

20 compounds were deliberately selected for this experiment. Some of them have a primary stress on the first element, some having double stress. The 20 compounds appear as follows:

(1) doorstep (2) loudspeaker (3) earthquake (4) hardworking (5) hairbrush

(6) homemade (7) drugstore (8) town hall (9) dining room (10) primer minister

(11) make-believe (12) old-fashioned (13) fountain pen (14) bad-tempered (15) fault finding

(16) second-class (17) grandmother (18) suitcase (19) red herring (20) heart-shaped

\section{Subjects}

40 students participated in this study. Among them 20 were college students, and the rest were from a middle school. All of them had learned English as a foreign language for at least 6 years, and none of them had prior information about the issue under examination. 


\section{Method}

Each subject was given 20 compounds as listed in materials and asked to mark the stress of each compound. After they completed the task, they were thanked and dismissed. Then an analysis of the experiment was performed.

Results and Discussion

The results of the analysis are presented in Table 3.

Table 3. The percentage of errors made for each compound

\begin{tabular}{lllllllllllllllllllll}
\hline Test Items & 1 & 2 & 3 & 4 & 5 & 6 & 7 & 8 & 9 & 10 & 11 & 12 & 13 & 14 & 15 & 16 & 17 & 18 & 19 & 20 \\
\hline $\begin{array}{l}\text { Percentage } \\
\text { of Errors } \\
\text { for Each }\end{array}$ & 60 & 0 & 40 & 10 & 50 & 20 & 70 & 0 & 70 & 17.5 & 100 & 12.5 & 100 & 25 & 90 & 22.5 & 87.5 & 75 & 32.5 & 90 \\
Item (\%) & & & & & & & & & & & & & & & & & & & & \\
\hline
\end{tabular}

The results in Table 3 show that the Chinese students' transference of the stress pattern of compounds in Chinese is apparently present in the production of their English counterparts. All the items with double stress pattern are basically well-produced, such as items $2,4,6,8,10,12,14,16,19$, but errors in stressing for the rest of the examples amount to a very high percentage. Due to the stress pattern of Chinese compounds, Chinese students are likely to use the w-s pattern instead of the s-w in English. Hence instead of producing the correct stress forms for the English compounds 'doorstep, 'earthquake, 'hairbrush, 'drugstore, 'dining room, 'make-believe, 'fountain pen, 'fault finding, 'grandmother, 'suitcase, 'heart-shaped, the students are liable to shift the main stress to the final syllable. Test items $2,4,6,8,10,12,14,16,19$ are well produced since they all share the similar stress patterns in Chinese and English.

Since Chinese is a syllable-timed language, Chinese learners of English may have difficulty producing English words and sentences in the way that corresponds to the characteristic rhythm of English. In addition to the word level, the interference of Chinese stress patterns in English learning also manifests itself at the sentence level, such as too many stresses in the utterances, applying pitch movements indiscriminately to syllables, pronouncing every word with equal stress, failure to reduce unstressed syllables, and failure to stress the right words in the sentences. All these work together to spoil the English speech rhythm, thus leading to a foreign accent. Since the Chinese stress pattern is inherent for Chinese students, the process of this transference is, to a large extent, unconscious. Chinese speakers' pronunciation of English words and sentences may sound staccato-like or sound distracting to the native speakers' ears, and this particular type of rhythm can adversely affect the comprehensibility of their English to the native speakers.

\section{Implications for English Pronunciation Teaching}

As mentioned above, English stress is difficult for Chinese EFL learners because they transfer their mother tongue stress patterns to English. Stress is one of the key suprasegmentals in English sound system, and plays an important role in intelligibility and comprehensibility. It is important for Chinese EFL learners to learn English stress. Therefore, more attention should be given to how to teach it effectively. The following are some implications for English pronunciation teaching.

\subsection{Placing More Emphasis on Suprasegmentals}

Pronunciation is a set of habits of producing sounds. Learning to pronounce a second language means building up new pronunciation habits and overcoming the bias of the first language (Cook, 1996). As everyone knows, once a bad habit is established, it may be difficult to change without serious effort. Then how to inhibit the interference from Chinese stress patterns in English pronunciation learning? The first and foremost, I think, is that English teachers must give more attention to suprasegmentals. A broad definition of pronunciation includes both suprasegmental and segmental features. It is important to remember that they all work in combination when we speak, and are therefore usually best learned as an integral part of spoken language. However, when teaching English to Chinese beginners, the teachers always give more attention to the isolated sounds or phonemes, but neglect the suprasegmental features. In their opinion, if a learner can pronounce each phoneme exactly, he will be able to pronounce the sequences of sounds or words fluently. This view leads to insufficient training in intonation. Therefore, having practiced all the sounds with considerable effort, the learners are dismayed to find that they still cannot monitor their rhythm of speech, let alone speak like the native speakers of English. Usually, 
being aware of the differences between L1 and L2 systems might be more beneficial than error correction. So it is the teacher's duty to illustrate the suprasegmental differences between Chinese and English to Chinese learners, especially the beginners, and help them master the English suprasegmental features through plenty of imitation and exercise.

\subsection{Being Qualified for English Pronunciation Instruction}

Teachers of pronunciation should keep themselves informed of the current research into the acquisition of second language phonology and bring teaching materials in line with the research findings; besides, teachers have to be trained in English pronunciation instruction and empowered with the theoretical knowledge of English sound system and the experience to teach English pronunciation well. Some teachers ignore the suprasegmentals in their pronunciation teaching just because they lack the confidence to teach them well. The teacher himself must have available an adequate description of English natural speech and have a beautiful English pronunciation. On the one hand, as teachers we need to make explicit the features of English sound system and teach stress rules to students (Kenworthy, 1987). On the other hand, the beautiful pronunciation of the English teacher will set a good example to his students and exert a great influence on his students' pronunciation both consciously and unconsciously. In foreign language learning, pronunciation is the one area where it is generally agreed that imitation is the essence of the learning process. The teacher often requires of his students the most accurate imitation of his own pronunciation, but since he himself is relatively uninformed about the features of English pronunciation, he is likely to transmit quite serious errors to his students, especially in the earlier stages of language learning. For example, in order to have himself heard clearly and imitated accurately, the teacher often slows his articulation below a normal conversational rate. In doing this, he may disturb the rhythm of English speech. When one deliberately slows his speech, there is a tendency to reduce the distinction between the time spent on stressed and unstressed syllables, and thus the stress system itself also becomes distorted and the natural rhythm is spoiled. However, experienced teachers can predict this potential error, and avoid it in their aim to increase intelligibility through clearer sounds.

\subsection{Motivating Learners to Improve Their Command of English Pronunciation}

As with all learning, motivation is a highly significant factor in pronunciation. The more it can be made necessary for the students to improve his speech, the more rewarding will the teaching be. The learning environment of most Chinese EFL learners is predominantly Chinese. They use Chinese for daily communication, and learn English mostly for entrance examinations of a higher grade. Chinese EFL learners could get access to English mainly in class, and under the influence of Chinese prosodic system, the restricted exposure to English makes it difficult for Chinese EFL learners to acquire native-like English rhythm. Motivation can be real or stimulated. Where it is possible, actual contact with native speakers in real communicative contexts is of course ideal. Where this is not possible, games in classroom that are designed to provide a context where communication is felt to depend on accurate speech will also be helpful. The trend towards greater use of communicative approach in language teaching makes it possible to incorporate more meaningful and communicative practice into materials for the teaching of pronunciation. Being aware of the importance of pronunciation in communication can encourage students to improve their pronunciation. Moreover, the teacher's dedication can also spur learners on to greater effort. The personality and attitude of the teacher often have a strong influence. When the students see that the teacher cares and is concerned and interested enough to react and respond to their pronunciation, they will make earnest efforts to improve.

\subsection{Providing More Time and Opportunities for Students to Practice}

Teachers should employ effective pronunciation teaching methods to help students perceive and produce the target sounds. For decades, teachers have supported their instruction by using audio, video, signal analysis software, and online resources. For example, the use of poetry and songs can make repetitive practice of rhythm and sound more natural and meaningful. Clear visual cues to students, such as underlining, using bold or capitals, circling or using ticks, clapping or tapping the relevant stress may help emphasize stress. With the wide use of computers in language teaching, the use of computerized material for pronunciation learning has been shown to be a promising area. Coniam (2002) explored EFL learners' attitudes towards suprasegmental features such as stress. He reported that the use of audio-visual software gave them a perspective that they had not been able to appreciate before. All in all, teachers should actively build the students' pronunciation awareness and confidence through practice in class, and encourage them repeatedly to monitor their own pronunciation as much as possible in and outside the classroom. But it should be remembered that English stress cannot be taught in isolation because stress is linked to other aspects of pronunciation, vocabulary learning and grammar. Whenever possible, stress should be taught with other skills, such as listening, speaking, and reading 
In summary, a qualified English teacher who has a good command of English, especially English pronunciation and a strong sense of responsibility should be arranged to teach the students at the beginner level. Only by doing this, can the students develop their awareness of intonation, lay a solid foundation for English pronunciation, and thus the goal of pronunciation teaching be achieved.

\section{Conclusion}

As we have seen in the preceding sections, many of the pronunciation difficulties in English stress are found to be a clear reflection of prosodic transfer of Chinese. Knowing the differences between Chinese and English stress can help teachers to identify reasons for Chinese EFL learners' pronunciation difficulties in English stress, and put forward effective strategies to promote the positive transfer, and inhibit the negative transfer in English pronunciation teaching and learning.

English stress plays an important role in intelligibility and comprehensibility. It deserves to be studied in all English classes, not just pronunciation classes. However, communicative aspect of language learning involves more than native-like accuracy of pronunciation, more emphasis should be placed on raising students' communicative competence, such as strategic, sociolinguistic, or cultural knowledge, so that what they produce would be more comprehensible to others.

\section{References}

Altmann, H. (2006). The perception and production of second language stress: A cross-linguistic experimental study. Delaware: University of Delaware. Retrieved from http://ling.uni-konstanz.De/pages/home/altmann/papers/Altmann-dissertation.Pdf

Archibald, J. (1997). The acquisition of English stress by speakers of nonaccentual languages: Lexical storage versus computation of stress. Linguistics, 35, 167-181. http://dx.doi.org/10.1515/ling.1997.35.1.167

Avery, P., \& Ehrlich, S. (1992). Teaching American English pronunciation. Oxford: Oxford University Press.

Brown, H. D. (1994). Principles of language learning and teaching. NJ: Prentice Hall.

Buren, P., \& Smith, M. (1985). The acquisition of preposition stranding by second language learners and parametric variation. Second language research, l(1), 18-46. http://dx.doi.org/10.1177/0267658308100289

Carrol, D. W. (2000). Psychology of Language (pp. 69, 85-86). Beijing: Foreign Language Teaching and Research Press.

Celce-Murcia, M., \& Hawkins, B. (1985). Contrastive analysis, error analysis, and interlanguage analysis. In M. Celce-Murcia (Eds.), Beyond basics: Issues and research in TESOL (pp. 6-77). Rowley, MA: Newbury House.

Chao, Y. R. (1968). A Grammar of Spoken Chinese. Berkeley, CA: University of California Press.

Chao, Y. R. (1980). Chinese tone and English stress. In L. R. Waugh, \& C. H. Van Schooneveld (Eds.), The Melody of Language (pp. 41-44). Baltimore, MD: University Park Press.

Chen, J. (1984). Spoken Chinese. Beijing: Beijing Press.

Chen, Y. (1987). A Comparison of Chinese and English Pitch. Foreign Language Education, 1, 20-29.

Cheng, C. C. (1973). A Synchronic Phonology of Mandarin Chinese. The Hague: Mouton.

Clark, J., \& Yallop, C. (2000). An Introduction to Phonetics and Phonology (pp. 340-357, 410-411). Beijing: Foreign Language Teaching and Research Press.

Coniam, D. (2002). Technology as an awareness-raising tool for sensitising teachers to features of stress and rhythm in English. Language Awareness, 11(1), 30-42.

Cook, V. (1996). Second Language Learning and Language Teaching. London: Arnold.

Corder, S. (1992). A role for the mother tongue. In S. Gass, \& L. Selinker (Eds.), Language transfer in language learning (pp. 18-31). Amsterdam: John Benjamin Publishing Company.

Cruttenden, A. (2001). Gimson's Pronunciation of English (pp. 221-235). Beijing: Foreign Language Teaching and Research Press.

Cruttenden, A. (2002). Intonation (pp. 13-18, 44). Beijing: Peking University Press.

Cutler, A., \& Carter, D. M. (1987). The predominance of strong initial syllables in the English vocabulary. Computer Speech and Language, 2, 133-142. Retrieved from http://pubman.mpdl.mpg.de/pubman/item/escidoc:68762:7/component/escidoc:68763/Cutler_1987_The+pr 
edominance.pdf

Ellis, R. (1994). The Study of Second Language Acquisition. Oxford: Oxford University Press.

Fan, C. Z. (1982). Sounds of English and Chinese. Primary and Middle School English Teaching and Research, $1,3-4$.

Fry, D. B. (1958). Experiments in the perception of stress. Language and Speech, 1, 126-152. http://dx.doi.org/10.1177/002383095800100207

Gao, L., \& Deng, Y. C. (2009). A corpus-based study on Chinese college students' word stress misplacement. Foreign Language World, 3, 10-16.

Garlson, R., Elenius, K., Granstrom, B., \& Hunnicutt, S. (1985). Phonetic and orthographic properties of the basic vocabulary of five European languages. In Quarterly progress and status report (Vol. 1, pp. 63-94). Stockholm: Speech Transmission Laboratory.

Gass, S. (1979). Language transfer and universal grammatical relations. Language Learning, 29, 327-344. http://dx.doi.org/10.1111/j.1467-1770.1979.tb01073.x

Gasser, M. (1990). Connectionism and universals of second language acquisition. In Studies in second language acquisition, 12(3), 179-199. Cambridge: Cambridge University Press.

Gong, K. J. (1991). Comparison of Chinese and English Intonation and English Intonation Teaching. Modern Foreign Languages, 3, 43-45.

Goodluck, H. (2000). Language Acquisition: A Linguistic Introduction (pp. 29-33, 42). Beijing: Foreign Language Teaching and Research Press.

Gui, C. K. (1978). A Comparison of Chinese and English Sound System. Modern Foreign Languages, 1, 44-50.

Guion, S. G. (2006). Knowledge of English stress in second language learners: First language and age of acquisition effects. Korean Journal of English Language and Linguistics, 6, 465-492.

Gussenhoven, C., \& Jacobs, H. (2001). Understanding Phonology (pp. 17, 206-220). Beijing: Foreign Language Teaching and Research Press.

He, S. F. (2002). Contrastive Analysis of English and Chinese. Shanghai: Shanghai Foreign Language Education Press.

Hu, Y. (1981). Modern Chinese. Shanghai: Shanghai Education Press.

Jin, D. Y. (1986). Exploring the origin of foreign accent. Language Teaching and Research, 4.

Juffs, A. (1990). Tone, syllable structure and interlanguage phonology: Chinese learners' stress errors. International Review of Applied Linguistics, 28(2), 99-118. http://dx.doi.org/10.1515/iral.1990.28.2.99

Kelly, G. (2000). How to teach pronunciation. Harlow: Longman.

Kenworthy, J. (1987). Teaching English pronunciation. Harlow: Longman.

Kuiper, K., \& Allen, W. S. (1996). An introduction to English language. London: Macmillan.

Language Transfer. (2013, September 10). In Wikipedia, the free encyclopedia. Retrieved September 10, 2013, from http://en.wikipedia.org/wiki/Language_Transfer

Larsen-Freeman, D., \& Long, M. (1991). An introduction to second language research. London: Longman.

Li, R. H. (1996). Comparative studies on Chinese and English Languages and Cultures. Shanghai: Shanghai Foreign Languages Education Press.

Li, X. Z. (1999). An Introduction to Language (p. 127). Shandong: Shandong University Press.

Lin, M. C., Yan, J. Z., \& Sun, G. H. (1984). A Primary Experiment on the Normal Stress of Disyllabic Words in Beijing Dialects. Dialects, 1, 57-73.

McCarthy, M. (1991). Discourse analysis for language teachers (p. 191). Cambridge: Cambridge University Press.

Odlin, T. (1989). Language transfer: Cross-linguistic influence in language learning. Cambridge, UK: Cambridge University press.

Ou, S. C. (2006). Factors and Mechanisms in L2 Word Stress Acquisition: Evidence from Chinese-English Interlanguage. Doctoral dissertation, University of Edinburgh. 
Purcell, E., \& Suter. R. (1980). Predictors of pronunciation accuracy: A reexamination. Language Learning, 30, 271-287. http://dx.doi.org/10.1111/j.1467-1770.1980.tb00319.x

Roach, P. (2003). Phonetics (pp. 31-33). Shanghai: Shanghai Foreign Language Education Press.

Scarcella, R. C., \& Oxford, R. L. (1992). The tapestry of language learning: The individual in the communicative classroom. Boston: Heinle \& Heinle.

Seferoglue, G. (2005). Improving students' pronunciation through accent reduction software. British Journal of Educational Technology, 36(2), 303-316. http://dx.doi.org/10.1111/j.1467-8535.2005.00459.x

Swan, M., \& Smith, B. (1987). Learner English: A teacher's guide to interference and other problems. Cambridge: Cambridge University Press.

Teschner, R. V., \& Whitley, M. S. (2004). Pronouncing English: A Stress-based Approach with CD-ROM. Washington DC: Georgetown University Press.

Trevian, I. (2007). Stress-neutral endings in contemporary British English: An updated overview. Language Sciences, 29, 426-450. http://dx.doi.org/10.1016/j.langsci.2006.12.016

Underhill, A. (1998). Sound foundation: Living phonology. Oxford: Heinemann.

Wang, G. Z. (1990). The characteristics of Chinese and English sound fluctuations and frequency mode and its influence on English Pronunciation Teaching. Modern Foreign Languages, 1, 89-100.

Wei, Z. C. (2003). An Introduction to Comparative Studies of Chinese and English. Shanghai: Shanghai Foreign Language Education Press.

Whitman, R., \& Jackson, K. (1972). The unpredictability of contrastive analysis. Language Learning, 22, 29-41. http://dx.doi.org/10.1111/j.1467-1770.1972.tb00071.x

Xu, S. (1980). An Introduction to Mandarin Phonetics. Beijing: Wenzi Gaige Press.

Yang, A. Z. (1987). An assessment of listening comprehension difficulties encountered by Chinese college English majors. Unpublished masters thesis, National Taiwan Normal University, Taiwan.

Zhao, Z. D. (2006). Phonology. Shanghai: Shanghai Foreign Language Education Press.

Zhou, D. (1980). An Introduction to the Pronunciation of Language Arts. Beijing: Chinese Social Science Press.

\section{Copyrights}

Copyright for this article is retained by the author(s), with first publication rights granted to the journal.

This is an open-access article distributed under the terms and conditions of the Creative Commons Attribution license (http://creativecommons.org/licenses/by/3.0/). 